\title{
Tailoring Haemophilia A prophylaxis with BAY 81-8973: a case series
}

Rita Carlotta Santoroa, Gaetano Giuffrida ${ }^{b}$, Filomena Daniele ${ }^{c}$, Fabio Gagliano ${ }^{d}$, Maria Francesca Mansueto $^{\mathrm{e}}$, Valeria Calafiore ${ }^{\mathrm{b}}$, Sergio Siragusa ${ }^{\mathrm{e}}$, Mariasanta Napolitano ${ }^{\mathrm{e}}$

a. Regional Hemophilia Center, Hemostasis and Thrombosis Unit, AOPC Pugliese-Ciaccio Hospital, Catanzaro, Italy

b University Hospital Policlinico Vittorio Emanuele, Catania, Italy

c. Hemostasis and Thrombosis Center, AO L'Annunziata Hospital, Cosenza, Italy

d Non-oncology Hematology Service, Pediatric Clinic, G. Di Cristina Hospital, ARNAS Palermo, Italy

e. Department of Health Promotion, Mother and Child Care, Internal Medicine and Medical Specialties, University of Palermo Hemophilia Center and Hematology Unit, University Hospital AOUP "P. Giaccone", Palermo, Italy

Text word count: 4297

Tables: 1

References:29

\section{Corresponding author}

Mariasanta Napolitano

University of Palermo

PROMISE Department

and 
Regional Hemophilia Center and Hematology Unit, University Hospital AOUP P. Giaccone, Palermo, Italy

Email: mariasanta.napolitano@unipa.it

\section{ABSTRACT}

BAY 81-8973 is an unmodified, full-length third generation recombinant factor VIII ( $\mathrm{FVVIII)}$ which offers a more favorable pharmacokinetic (PK) profile, compared to its predecessor sucrose-formulated rFVIII (rFVIII-FS). We here report on a retrospective case series of nine patients affected by hemophilia $A(H A)$, with variable disease severity, bleeding phenotype and comorbidities, to underline our clinical practice on prophylaxis with a recently introduced standard hall-life recombinant Factor VIII. The current case series highlights how the current clinical management of hemophilia is able to personalize treatment in several specific conditions like concomitant illnesses with thrombotic risk and allergic reactions.

Keywords: Hemophilia A, hemarthrosis, hemophilic arthropathy, rFVIII, pharmacokinetic;prophylaxis. 


\section{Introduction}

Hemophilia $A(H A)$ is a congenital bleeding disorder resulting from absence or deficiency of clotting factor VIII (FVIII). The symptoms consist of more or less severe hemorrhages as a result of trauma, surgical procedures, or spontaneous bleedings. These most likely occur into the joints (hemarthrosis) leading over the long term to progressive and irreversible hemophilic arthropathy, but bleeding may also occur into muscles, soft tissues and other sites (e.g. central nervous system) with potentially life-threatening consequences and, not least, drastic impairment in the individual's quality of life (QoL) [1].

The severity of bleeding phenotype depends on the degree of FVIII deficiency, or rather on the residual amount of FVIII plasma concentration, which classifies the disease as mild (FVIII ranges between 6 and $40 \mathrm{IU} / \mathrm{dL}$ ), moderate (FVIII from 1 to $5 \mathrm{IU} / \mathrm{dL}$ ) and severe (FVIII $<1 \mathrm{IU} / \mathrm{dL})[1]$.

The prevalence of HA is approximately 1:7,500 males. The severe forms are usually diagnosed during the first year of life due to abnormal subcutaneous hematomas or hemarthroses, which may occur after minor trauma, or spontaneously [2].

Current guidelines for the management of patients with severe HA recommend prophylaxis with intravenous (IV) administration of FVIII concentrates in order to prevent spontaneous hemarthroses, preserve healthy joints, reduce the incidence of hemophilic arthropathy and improve QoL [3-8]. In patients with severe hemophilia, the success of prophylaxis depends on the maintenance of values of FVIII above the threshold of $1 \mathrm{IU} / \mathrm{dL}$, based on early observations that patients with moderate HA rarely bleed and experience chronic 
arthropathy [9]. Prophylaxis regimen with standard half-life concentrates is based on intravenous infusion of 25-40 IU/kg FVIII concentrates two or three times per week on nonconsecutive days, or every other day, representing a serious burden that significantly impacts the patient's QoL. Furthermore, more recent findings suggest that patients could benefit from regimens that increase the trough FVIII level activity above $1 \mathrm{IU} / \mathrm{dL}$ (e.g. 3 or $5 \mathrm{IU} / \mathrm{dL}$ ), to prevent breakthrough bleeding experienced sometimes despite a continuous prophylactic treatment $[10,11]$. This approach takes into consideration the heterogeneity of the disease due to patients' characteristics and needs, including age, physical activity and bleeding frequency.

The recently introduced half-life extension technologies have allowed the development of a first generation of long-acting FVIII concentrates with improved circulating survival [12]. However, the half-life extension of such FVIII was not as efficient as initially expected. for example, $r F V I I I F c$ fusion protein $\left(\mathrm{rFVIII-Fc}\right.$, Elocta $\left.{ }^{\circledR}\right)$, the only extended half-life $\mathrm{rFVIII}$ currently reimbursed in Italy, requires the administration of routine prophylaxis at the dosage of $50 \mathrm{IU} / \mathrm{kg}$ every four days, with the possibility to adjust the dose (25-65 IU/kg at 3-5 days' intervals) based on patient response.

\subsubsection{BAY 81-8973 (KOVALTRY®), A MODERN rFVIII}

One of the most recently approved rFVIII is BAY 81-8973 (Kovaltry ${ }^{\circledR}$, Bayer, Berkley, CA, USA), which represents the evolution of Bayer's well-established rFVIII-FS (Kogenate ${ }^{\circledR} F S$, Bayer, Berkley, CA, USA) [2,5,7,13-20]. Despite being produced in the same baby hamster cells, compared with its predecessor rFVIII-FS, BAY 81-8973 is produced by modernized manufacturing technologies which eliminate the use of human- and/or animal-derived raw materials from the manufacturing process (third generation replacement FVIII), decreasing the risk for anti-FVIII antibodies (inhibitors) development and yielding a better safety profile 
[19]. Moreover, it is known that concentrates with a higher von Willenbrand factor (VWF) content are associated to lower inhibitor development. Although BAY 81-8973 does not contain VWF, the molecule's characteristics (consistent glycosylation and sulfation of 6 tyrosine sites, which make it more similar to endogenous FVIII) increase its affinity for the patient's VWF compared to other rFVIII, which may prevent inhibitor development [8]. Regarding the manufacturing process, two other characteristics need to be underlined from a pharmacokinetic (PK) point of view. First, BAY 81-8973 is a full-length rFVIII presenting glycans shifted to higher branched structures and slightly higher sialylation, which contribute to an improved PK profile, including slower clearance, higher area under the curve (AUC), and longer half-life ( $t_{1 / 2}$, mean 13.8 vs 12 hours) $[13,20,21]$. Second, its characteristics are further enhanced by the presence in the cells of the gene for human heat shock protein 70 (HPS70), which is essential for proper protein folding and increases FVIII expression. Data from comparative studies have confirmed PK parameters for BAY 89-8173 to be non-inferior to - and for some PK variables significantly better than - those for rFVIII-FS and another commercial unmodified rFVIII (antihemophilic factor (recombinant) plasma/albumin-free method, rAHF-PFM, Advate ${ }^{\circledR}$ ) in terms of higher AUC, prolonged $\mathrm{t}_{1 / 2}$ and mean residence time (MRT) after IV injection, and slower clearance [8 The safety and efficacy of BAY 81-8973 have been extensively studied in the LEOPOLD (Long-Term Efficacy Open-Label Program in Severe Hemophilia A Disease) international clinical development program $[20,21,22,23]$, encompassing three separate trial segments in patients affected by severe HA: LEOPOLD I (part A: PK profile; part B: safety and efficacy in prophylaxis; part C: hemostasis during surgery and extension), LEOPOLD II (randomization to: on demand, low and high dose prophylaxis) and LEOPOLD KIDS (part A: PK profile, safety and efficacy in prophylaxis in previously treated patients; part B: PK profile, safety and efficacy in prophylaxis in previously untreated patients and extension) $[22,23]$. 
The LEOPOLD I and II enrolled over 120 adolescent and adult patients with HA (12 to 65, mean age 30 years) featuring a compromised and difficult to manage joint status, most with target joints (71\% Leopold I and $89.9 \%$ Leopold II). Of note, in these two clinical trials BAY 81-8973 demonstrated to effectively prevent bleeding episodes with both a twiceweekly and three-times-weekly dosing prophylactic regimen $[8,20,23]$.

Here we describe a retrospective case series of 9 patients affected by HA, with variable disease severity, bleeding phenotype and/or comorbid conditions, to outline our clinical practice on BAY 81-8973 prophylaxis. We believe it is important to stress how observed treatment outcome is often subject to individual PK response to FVIII, and requires dosing regimens to be adjusted according to variables such as age, joint status, activity index, bleeding phenotype, adherence and other biasing factors [23; 24].

\subsubsection{CASE PRESENTATIONS}

The cases presented describe 9 patients (males, mean \pm SD age $48.9 \pm 15.9$ years) with HA and variable disease severity, different bleeding phenotype and different clinical history, as described in Table 1. Patients did not have a previous history of inhibitor. All patients received treatment at least with another FVIII concentrate before switching to BAY 81-8973. The switch to BAY 81-8973 was proposed by caring hematologist to attain better PK parameters and/or to improve patient clinical and functional outcomes (specifically, reduction in annual bleeding rate $-\mathrm{ABR}-$ and longer intra-infusion interval).

PK profiles are summarized in Figure 1. Individual PK evaluations were performed by means of the advanced WinNonlin software and/or WAPPS calculator, except for one case. Joint health was evaluated by using the Hemophilia Joint Health Score (HJHS), the Petterson score or the Hemophilia Early Arthropathy Detection with Ultrasound (HEADUS) score, as appropriate. 
The cases described herein are reported in accordance to the CARE guidelines, as applicable. All information collected has been handled confidentially and is presented in order to safeguard patient identity. All patients signed an informed consent.

1.1.3Case 1: 54 -year-old male labor worker, with severe HA not complicated by inhibitor development. The patient presented obesity, chronic HCV-related hepatitis treated with interferon and ribavirin, arterial hypertension, and diabetes. He received on-demand treatment with FVIII until the year 2000, when he then started secondary prophylaxis with rAHF-PFM $40 \mathrm{IU} / \mathrm{kg}$ three times per week, though with poor adherence. In 2007, he underwent left knee-replacement arthroplasty. In 2015, after recurrent joint bleeding episodes $(A B R=3)$, worsening of hemophilic arthropathy $(H J H S=25)$ and onset of chronic pain to his left ankle, the prophylactic regimen was potentiated to a dose of $40 \mathrm{IU} / \mathrm{kg}$ three times per week. In 2017, in view of switching to BAY 81-8973, a PK study was done to compare previous and current treatments. After an appropriate wash-out period, PK parameters were measured after IV administration of rAHF-PFM $40 \mathrm{IU} / \mathrm{kg}$ and BAY 81$897350 \mathrm{IU} / \mathrm{kg}$. As evidenced by WinNonlin analysis, BAY 81-8973 led to a significant improvement of main PK parameters: MRT 22.52 vs 6.72 hrs, clearance 0.01 vs 0.03 $\mathrm{dL} / \mathrm{h} / \mathrm{Kg}$ and $\mathrm{t}_{1 / 2} 15.99$ vs $7.08 \mathrm{hrs}$, with a $1.2 \mathrm{IU} / \mathrm{dL}$ trough level $96 \mathrm{hrs}$ post-BAY 81-8973 infusion. As to BAY 81-8973, WAPPS showed a $\mathrm{t}_{1 / 2}$ of $18.25 \mathrm{hrs}(95 \% \mathrm{Cl} 17.00-19.25)$ and a "time to" $1 \mathrm{IU} / \mathrm{dL}, 2 \mathrm{IU} / \mathrm{dL}$ and $5 \mathrm{IU} / \mathrm{dL}$ of 136, 108 and $79 \mathrm{hrs,} \mathrm{respectively.} \mathrm{Accordingly,}$ from March 2017 the patient continued prophylaxis with BAY 81-8973 $45 \mathrm{IU} / \mathrm{kg}$ twice a week.

In June 2017, during endoscopic examination and transgastric biopsy, the patient was diagnosed a pancreatic malignancy and started for it chemotherapy in September 2017. The patient continued prophylaxis throughout chemotherapy and after, with no hemorrhage, 
except for one episode of melena during the first cycle of chemotherapy linked to erosive gastritis. The patient is still under treatment for pancreatic carcinoma.

1.1.4Case 2: 35-year-old male, employee, affected by severe HA diagnosed at the age of 1 year. Since then, he was treated on-demand with plasmaderived FVIII (pdFVIII, Haemate- $\mathrm{P}^{\circledR}$ ) with no evidence of inhibitor development. Over the years, he developed hemophilic arthropathy mostly of the knees (especially right one). In December 2016, the patient began to experience pain during walking and standing. A physical examination confirmed the presence of severe joint impairment with limited limb extension (10-90 $)$. A radiographic assessment showed bone loss at the femur, with a Petterson score of 13 at the right knee and 10 at the left one. Hence, he agreed to secondary prophylaxis. The patient received pdFVIII treatment at the dose of $35 \mathrm{IU} / \mathrm{kg}$ every other day and underwent a program of functional physical rehabilitation. Upon reactivation of an infection by human cytomegalovirus contracted many years earlier, the patient received antiviral treatment which permanently eradicated the virus; however, during the first month of antiviral treatment the patient manifested severe allergic reaction to pdFVIII, characterized by a widespread itchy urticarial rash and hypotension, suggesting a reaction mediated by IgE plasma protein. Accordingly, prophylactic treatment was temporarily suspended. The previous pdFVIII treatment was replaced with BAY 81-8973 in consideration of its lack of human or animal-derived proteins. The first infusion was performed in hospital in the intensive care unit. The initial dose established was $40 \mathrm{IU} / \mathrm{kg}$ every other day, but it was later reduced to two infusions per week, based on the favorable PK parameters (the PK parameters were elaborated starting from the laboratory data using the common mathematical methods without the help of dedicated software, considering the classic pharmacokinetic models with one and two compartments with determination of concentration logarithm, intravascular and extravascular administration). 
During the following months, the patient was closely monitored for inhibitor development, which, however, did not occur. Joint function improved, and Petterson score for the right and left knee decreased from 13 and 10 to 9 and 7, respectively. No adverse therapyrelated reactions were reported after this switch.

1.1.5Case 3: 48-year-old male with moderate HA, diagnosed at age of 2 years, history of allergic reactions to pdFVIII. No signs of hemophilic arthropathy, but frequent hematomas of the lower limbs. Occasional sports activity. Until September 2014, he received hospitalbased treatment with rFVIII-FS. In November 2014, after repeated muscle hematomas (ABR 4) that required daily substitution therapy, the patient agreed to secondary prophylaxis with $50 \mathrm{IU} / \mathrm{kg}$ FVIII-FS twice a week, foreseeing the same in-hospital premedication procedure (initially with antihistamine and steroid, and then with antihistamine alone). After four months of prophylaxis, despite the benefits obtained in terms of reduction in bleeding frequency, the patient decided to interrupt his prophylaxis due to the burden of frequent infusions and in-hospital premedication. Two years later, in March 2017 the patient was proposed to switch to BAY 81-8973 and to try again prophylaxis, in virtue of the product's higher purity and lower risk of allergic reaction. The patient began prophylaxis with $50 \mathrm{IU} / \mathrm{kg}$ twice a week and was progressively able to abandon in-hospital premedication within two months from treatment initiation. The PK study on BAY 81-8973 yielded a $t_{1 / 2}>12 \mathrm{~h}$ and return to baseline FVIII (4 IU/dL) after $72 \mathrm{~h}$.

1.1.6 Case 4: 25-year-old male, affected by severe HA; moderate physical activity (yoga). For many years he received prophylaxis with $\mathrm{rFVIII-FS} 30 \mathrm{IU} / \mathrm{kg}$ three times per week achieving $A B R=0$. FVIII trough levels resulted $<1 \mathrm{IU} / \mathrm{dL}$ at $48 \mathrm{~h}$ after the last infusion, the patient was recommended to switch to BAY $81-8973$ at the same dosing regimen. Following this switch, the FVIII recovery improved, and trough levels raised to $2 \mathrm{IU} / \mathrm{dL}$. 
1.1.7Case 5: 56-year-old man with mild/moderate HA. He received on-demand treatment due to a mild bleeding phenotype (ABR 0 ) and the absence of target joints. Upon medical examination, he was diagnosed with hypertension in December 2014. Due to unstable angina he underwent percutaneous coronary intervention. After surgery, the patient started antiplatelet therapy and secondary prophylaxis with rFVIII (Helixate $\left.{ }^{\circledR}\right)$ at the dosage of 20 $\mathrm{IU} / \mathrm{kg}$, three times per week. During later cardiologic assessments, he was diagnosed with stress ischemia, restenosis of the anterior interventricular artery (IVA) and right coronary and de novo stenosis of the proximal IVA. Accordingly, he underwent transluminal percutaneous coronary angioplasty with a drug-eluting stent (DES) on IVA and Drugeluting balloon (DEB) on the right coronary and prescribed dual antiplatelet therapy (DAPT, aspirin plus clopidogrel). To minimize the risk of bleeding due to DAPT in a patient with an underlying bleeding disorder, the PK profile was evaluated, and treatment was switched to prophylaxis with BAY 81-8973 at the dosage of $20 \mathrm{IU} / \mathrm{kg}$, three times per week. Compliance to treatment was good and a first laboratory result confirmed FVIII trough levels of $7 \mathrm{IU} / \mathrm{dL}$. A second PK evaluation repeated after several months showed a FVIII trough levels of 12 $\mathrm{IU} / \mathrm{dL}$, a $24 \mathrm{~h}$ half-life and return to baseline FVIII levels after approximately 96 hours.

1.1.8 Case 6: 53-year-old male with moderate $\mathrm{HA}$ and a job requiring heavy works. In the past he was treated on-demand and later on secondary prophylaxis with rFVIII-FS at the dosage of $30 \mathrm{lU} / \mathrm{kg}$, twice a week, attaining an $A B R$ of 3-4, with bleeding mostly occurring at the elbows and ankles and a $6 \mathrm{IU} / \mathrm{dL}$ trough level. Following ultrasound examination and HEAD-US score confirming the presence of hemophilic arthropathy, the patient was switched to BAY 81-8973 $25 \mathrm{IU} / \mathrm{kg}$ twice a week in attempt to provide him a better protection against bleeding episodes. The efficacy of the new treatment was evaluated by means of PK study, comparing rFVIII-FS $30 \mathrm{IU} / \mathrm{kg}$ to BAY $81-897325 \mathrm{IU} / \mathrm{kg}$. PK parameters 
for these two products were similar at $48 \mathrm{~h}$, while FVIII at 72 hrs was higher for BAY 81 8973, being $5.9 \mathrm{IU} / \mathrm{dL}$.

1.1.9 Case 7: 61-year-old with moderate HA. Treated for many years on-demand and later on secondary prophylaxis with $\mathrm{rFVIII-FS} 30 \mathrm{IU} / \mathrm{kg}$ twice a week, attaining an ABR of 2-3, with hemarthrosis of ankles and knees and a FVIII through level of $6 \mathrm{IU} / \mathrm{dL}$. By ultrasound examination of joints with HEAD-US score calculation, hemophilic arthropathy was confirmed, the patient was switched to BAY 81-8973 at the dosage of $30 \mathrm{IU} / \mathrm{kg}$ twice a week in order to provide a better protection against bleeding episodes. The efficacy of the new treatment was evaluated by means of PK study, comparing $30 \mathrm{IU} / \mathrm{kg}$ of both $\mathrm{rFVIII-FS}$ and BAY 81-8973. PK parameters showed a slightly better performance in favor of rFVIIIFS until 48 hrs post-infusion, but a FVIII at 96 hours after BAY $81-8973$ of $5.9 \mathrm{IU} / \mathrm{dL}$.

1.1.10 Case 8: 17-year-old male with severe HA diagnosed at birth. At the age of 1 year, he started prophylaxis treatment with a non-specified $\mathrm{rFVIII}$ at the dose of $30 \mathrm{IU} / \mathrm{kg}$ per infusion, without inhibitor development. Between 2011 and 2015, he received rFVIII-FS at the dosage of $30 \mathrm{IU} / \mathrm{kg}$ three times per week, attaining an $A B R=2$, showing excellent adherence to therapy. without target joints. In 2015, he complained of osteoarticular pain in particular of the knees. X-ray and ultrasound examination showed the presence of diffuse synovial hypertrophy; for this reason, prophylaxis was intensified to every other day. In July 2017, treatment was switched to BAY 81-8973 $30 \mathrm{lU} / \mathrm{kg}$ twice a week, attaining an $\mathrm{ABR}=0$. Comparison of PK assessment showed FVIII levels of $43 \mathrm{IU} / \mathrm{dL}$ at $4 \mathrm{hrs}, 9.7 \mathrm{IU} / \mathrm{dL}$ at $24 \mathrm{hrs}$ and $0.1 \mathrm{IU} / \mathrm{dL}$ at $48 \mathrm{hrs}$ with rFVIII-FS; however, after switch to BAY 81-8973, FVIII levels increased to $67.6 \mathrm{IU} / \mathrm{dL}$ at 4 hours, $8.4 \mathrm{IU} / \mathrm{dL}$ at 48 hours and $4.4 \mathrm{IU} / \mathrm{dL}$ at 72 hours, once the steady state was reached. 
1.1.11 Case 9: 28-year-old male with severe HA diagnosed within the first year of life. The patient had no history of inhibitors, under prophylaxis with rFVIII-FS $30 \mathrm{IU} / \mathrm{kg}$ three times per week. He switched to BAY 81-8973 $30 \mathrm{IU} / \mathrm{kg}$ three times per week. PK parameters with rFVIII-FS showed FVIII levels of $23.9 \mathrm{IU} / \mathrm{dL}$ at 4 hours, $1.2 \mathrm{IU} / \mathrm{dL}$ at 48 hours and $0.4 \mathrm{IU} / \mathrm{dL}$ at 72 hours. After switch to BAY 81-8973, PK assessment showed FVIII levels of 34.4 $\mathrm{IU} / \mathrm{dL}$ at $4 \mathrm{hrs}, 4.5 \mathrm{IU} / \mathrm{dL}$ at $48 \mathrm{hrs}$ and $1.7 \mathrm{IU} / \mathrm{dL}$ at $72 \mathrm{hrs}$.

\section{DISCUSSION}

In the last years, the prognosis of HA has dramatically improved thanks to the access to prophylaxis and newer generations of rFVIII. Although prophylaxis cannot reverse established joint damage in patients with long-standing disease, it has shown to effectively stabilize FVIII activity enough to decrease the frequency of bleeding and slow progression of joint disease. Indeed, early intervention at young age is largely encouraged by guidelines. Compliance to prophylaxis infusion schedules is equally important, given that outcomes have shown to be influenced by the time spent below Factor VIII trough levels, due to increased breakthrough bleeds and hemarthroses [9,24,25].

As broadly acknowledged, individual response to injected FVIII is variable, and patients under the same prophylaxis schedule may exhibit widely variable trough levels. Pharmacokinetic studies have found that the age of the patient influences FVIIII clearance and half-life, with aging patients showing reduced FVIII clearance and increased half-life [24,25]. Accordingly, age-dependent changes in FVIII half-life appear to also impact the FVIII dosing regimen (units per $\mathrm{Kg}$ of body weight) required to maintain a trough level throughout prophylaxis. Weight also appears to have a role in individual variability, suggesting weight-based dose adjustments in overweight and obese patients [24]. However, because clinical bleeding patterns may significantly differ in patients having 
similar coagulation factor activity, in addition to individual PK data, dosing is further tailored following a multidimensional approach considering bleeding pattern (frequency of bleeding episodes, hemarthrosis, affected joints), clinical history (age at first bleeding; orthopedic and instrumental scores, concentrate consumption), clinical response to treatment, and patient's life-style or needs [24]. In fact, although treatment efficacy is generally measured by PK parameters and infusion frequency, it is also true that while one patient might prefer fewer weekly infusions, another may need higher trough levels to contrast subclinical traumas caused by physical or occupational activities [24].

Currently, individualized adjustments to FVIII replacement regimens are more and more often established by use of dedicated software able to handle the complex aspects of PK, and with a much lower number of blood samples -and less inconvenience for the patientthan needed applying traditional PK study methods [24]. This approach helps hematologists to establish the most effective dose for patient and to decide on extension of injection intervals, and foresee outcome more reliably.

Kovaltry represents a valid option in terms of effectiveness and safety of prophylaxis. Its full-length unmodified rFVIII molecular structure has led to an improvement in patients' PK parameters, with a longer half-life and a reduced clearance, allows to reduce infusion rate (dosing as few as twice weekly). Extended half-life (EHL) Factor VIII drugs are now becoming commercially available in several countries and they represent a valid option to reach higher, stable levels of coagulation Factor VIII with fewer (from twice to once weekly) infusions, however they are not all approved for patients aged<12 years and long-term data on their safety are not yet available. BAY 81-8973 thus remains a valuable treatment option, allowing to define schedules based on individual patients, treatment history, and clinical presentation.

\subsubsection{Improved PK and ABR in different bleeding phenotypes}


Variability in individual response to FVIII treatment between individuals can be observed among the cases presented. As expected, in persons presenting the same grade of disease, higher doses of FVIII were required in younger vs older patients, and in patients overweight $v s$. within normal weight range.

Current dosing recommendations suggest FVIII doses ranged from 25 to $40 \mathrm{IU} / \mathrm{Kg}$, yet slightly higher doses were needed to accommodate the patient's needs. The patient in case 1 featured high weight (case 1), severe $\mathrm{HA}$, and ongoing anticancer treatment; the patient in case 3 was affected by moderate $\mathrm{HA}$, but dosage of $50 \mathrm{IU} / \mathrm{Kg}$ allowed two infusions weekly (FVIII:C= $4 \%$ at $72 \mathrm{~h}$ ).

With specific reference to effectiveness in terms of PK parameters, in case n. 1 treatment with Kovaltry® yielded a threefold MRT, and a twofold $t_{1 / 2}$. This improved PK profile reduced intermittent bleeding episodes, improving the patient's quality of life.

An example of variability in bleeding phenotypes can be observed in the cases of the three young adults affected by severe HA (cases 4, 8, 9). All three patients had been on treatment with Kogenate ${ }^{\circledR}$ at the dosage of $30 \mathrm{IU} / \mathrm{Kg}$, three times/week for several years: while a 25-year old patient had attained an ABR of 0 , the 17 years old patient maintained an ABR of 2. Treatment switch to BAY 81-8973 resulted in ABR of zero in all cases, even though with different FVIII:C levels after 48 hours (1\%, 4.4\%, and 4.5\% respectively) [24]. The benefits of a better PK profile are not only remarkable for patients with severe HA, but also for those with moderate HA (cases n. 5, 6, 7). Currently, a revaluation of the optimal trough levels is ongoing, this to set as goal not only bleeding episodes prevention, but also improvement of arthropathy and subclinical bleedings control. Ideally, patients with severe HA should be treated for prophylaxis to attain FVIII:C $>15 \%$ but the goal could be too ambitious due to cost issues.

\subsubsection{Hemophilia management and cancer treatment}


The management of hemophilic cancer patients is a quite new and relevant aspect of hemophilia care, this issue has been recently discussed in a multicenter Italian study by Taliaferro et al.[26] In the above reported study, authors noted that hemophiliac cancer patients do not usually receive antihaemorrhagic prophylaxis during treatment of the underlying cancer, and that patients with concomitant inhibitor are not usually referred to chemo or radiotherapy, suggesting the lack of a proper prophylactic treatment schedule in this subset of patient and the missed opportunity for a proper treatment of the underlying cancer. Accordingly, prior stabilization of FVIII activity through prophylaxis becomes crucial. This was the case 1 description, where stabilization facilitated HA management in the planning of surgical interventions and anticancer treatment. Treatment burden was also reduced, with fewer infusions for the patient, which is particularly relevant in the case of oncological patients already exposed to several physically demanding treatments.

Of note, in the study by Tagliaferri et al, authors also reported a higher rate of virus-related cancers among patients with severe hemophilia and lower rates of non-virus-related cancers, which decreased with the increase of disease severity. Nowadays, FVIII production technologies have overcome the risks of infection and other safety concerns, which further facilitates long-term patient management.

\subsubsection{Cardiovascular disease}

Stabilization of FVIII activity has also a central role in the outcome of several diseases and chronic conditions ensuing with aging. Patients with hemophilia may have a lower cardiovascular mortality but they have the same high prevalence of subclinical atherosclerosis as the general population [27]. Nowadays, persons with hemophilia actually present the same risk of cardiovascular disease (CVD) as the healthy population. 
Among all cardiovascular risk factors, hypertension is quite common in hemophilia, it not only increases the risk of cardiovascular (CV) diseases, but also the risk of intracerebral bleeding [27]. Moreover, as life expectancy among persons with HA is increasing, there is a growing need to monitor individuals also for CV risk. Indeed, as evidenced in case 5, another very relevant aspect was the possibility of modulating prophylaxis in patients receiving antiplatelet and anticoagulant treatments. FVIII activity must also be monitored over time in order to detect any change in PK/PD profile and adjust treatment accordingly. Also in this case, stabilization of FVIII activity allows better planning of surgical interventions and related therapeutic adjustments.

\subsubsection{Allergic reactions}

Just as relevant, BAY 81-8973 also features a better safety profile in terms of a reduced risk of allergic reactions triggered by the replacement treatment (cases 2 and 3 ). Available data on this issue are quite scant. Generally, allergic reactions are more common in hemophilia B and they rarely occur in HA patients treated with FVIII. Allergic reactions to FVIII replacement treatment have been previously described by a retrospective study [28] on patients treated with plasma derived-FVIII (pd-FVIII). Based on results of the anti-FVIII immunoglobulin profile, the reported allergic reactions were triggered by other proteins contained in pd-FVII, thus they were not directed against FVIII [28]. The differentiated immunogenicity for pdFVIII and rFVIII was further described by Lai et al, though the exact mechanisms are still to be defined [29].

Importantly, the switch to BAY 81-8973 in our cases allowed to avoid the need for inhospital support to prophylaxis, which was an important aspect both for the two patients with severe and moderate HA, respectively. Moreover, prophylaxis with BAY 81-8973 in 
the described case 2 , allowed the patient to partially recover joint function, as confirmed by the improved Petterson score.

\subsubsection{Conclusions}

Overall, the use of this the third-generation recombinant factor BAY 81-8973 allows to reduce infusion rate and tailor dose according to a multidimensional approach considering PK parameters, variability in bleeding phenotype, age, weight, and patient's lifestyle, allowing patients to attain improved joint function, and increase of quality of life. Benefits were evident both for severe and moderate HA.

\section{Acknowledgments}

Authors are grateful to ERA SRL. for editorial support and English revision of the manuscript.

\section{Fundings}

This research did not receive any specific grant from funding agencies in the public, commercial, or not-for-profit sectors.

\section{Disclosure}

MN acted as consultant for Bayer, BIOFVIIIx, Novonordisk, Amgen, and received speaker fees from: Kedrion, Octapharma, Baxalta, CSLBehring, Novonordisk, Bayer.

SS acted as consultant for Bayer, BIOFVIIx, Novonordisk and received speaker fees by: Kedrion, Octapharma, Amgen, Baxalta, CSLBehring, Novonordisk, Bayer, Novartis. All other authors have no relevant conflicts of interest to declare 


\section{References}

1. Srivastava A, Brewer AK, Mauser-Bunschoten EP, Key NS, Kitchen S, Llinas A, et al. Guidelines for the management of hemophilia. Hemophilia 2013; 19: e1-e47.

2. Ljung RCR. Prevention and management of bleeding episodes in children with hemophilia. Paediatr Drugs 2018; 20(5): 455-464.

3. Guideline on the clinical investigation of recombinant and human plasma-derived factor VIII products. Committee for Medicinal Products for Human Use (CHMP) EMA/CHMP/BPWP/144533/2009 rev. 2.26 July 2018

4. Rocino A, Coppola A, Franchini M, Castaman G, Santoro C, Zanon E et al. Principles of treatment and update of recommendations for the management of haemophilia and congenital bleeding disorders in Italy. Blood Transfusion 2014; 12: $575-598$.

5. Manco-Johnson MJ, Kempton CL, Reding MT, Lissitchkov T, Goranov S, Gercheva L, et al. Randomized, controlled, parallel-group trial of routine prophylaxis vs. ondemand treatment with sucrose-formulated recombinant factor VIII in adults with severe hemophilia A (SPINART). J ThrombHaemost 2013; 11: 119-1127. 
6. Manco-Johnson MJ, Abshire TC, Shapiro AD, Riske B, Hacker MR, Kilcoyne R, et al. Prophylaxis versus episodic treatment to prevent joint disease in boys with severe hemophilia. N Engl J Med 2007; 357: 535-544.

7. Schiavoni M, Napolitano M, Giuffrida G, Coluccia A, Siragusa S, Calafiore V, et al. Status of Recombinant Factor VIII Concentrate Treatment for Hemophilia a in Italy: Characteristics and Clinical Benefits.Front Med (Lausanne). 2019 Dec 3; 6:261

8. Mahlangu JN, Ahuja SP, Windyga J, Church N, Shah A and Schwartz L. BAY 818973, a full-length recombinant factor VIII for the treatment of hemophilia A: product review. TherAdvHematol 2018; 9 (7): 191-205.

9. Collins PW, Blanchette V, Fischer K, Björkman S, Oh M, Fritsch Set al. Breakthrough bleeding in relation to predicted factor VIII levels in patients receiving prophylactic treatment for severe hemophilia A. J Thromb Haemost 2009; 7: 41320.

10.Den Uijl E, Mauser Bunschoten E, Roosendaal G, Schutgens RE, Biesma DH, Grobbee DE, et al, Clinical severity of haemophilia A: does the classification of the 1950s still stand? Haemophilia 2011, 17: 849-853.

11. Jimenez-Yuste V, Auerswald G, Benson G, Lambert T, Morfini M, Remor E et al. Achieving and maintaining an optimal trough level for prophylaxis in haemophilia: the past, the present and the future. Blood Transfus 2014; 12: 314-9 
12. Mancuso ME, Santagostino E. Outcome of clinical trials with new extended halflife FVIII/IX Concentrates. J Clin Med. 2017 Mar 28;6(4). pii: E39

13. Shah A, Delesen H, Garger S, Lalezari S. Pharmacokinetic properties of BAY 818973, a full-length recombinant factor VIII. Haemophilia. 2015 Nov;21(6):766-71

14. Kreuz W, Gill JC, Rothschild C, Lusher JM, Kellermann E, Gorina E, et al. Fulllength sucrose-formulated recombinant factor VIII for treatment of previously untreated or minimally treated young children with severe haemophilia A: results of an international clinical investigation. ThrombHaemost 2005; 93: 457-467.

15. Collins P, Faradji A, Morfini M, Enriquez MM, Schwartz L. Efficacy and safety of secondary prophylactic vs. on-demand sucrose-formulated recombinant factor VIII treatment in adults with severe hemophilia A: results from a 13-month crossover study. J Thromb Haemost. 2010:83-9.

16. Abshire TC, Brackmann HH, Scharrer I, Hoots K, Gazengel C, Powell JS et al. Sucrose formulated recombinant human antihemophilic factor VIII is safe and efficacious for treatment of hemophilia A in home therapy: International KogenateFS Study Group. Thromb Haemost 2000; 83: 811-816.

17. Lusher J, Abildgaard C, Arkins S, Mannucci PM, Zimmermann R, Schwartz L, et al. Human recombinant DNA-derived antihemophilic factor in treatment of previously untreated patients with hemophilia: final report on a hallmark clinical investigation. J ThrombHaemost 2004; 2: 574-583. 
18. Lusher J, Arkins S, Abildgaard CF, Schwartz RS. Recombinant factor VIII for the treatment of previously untreated patients with hemophilia A: safety, efficacy, and development of inhibitors. Kogenate Previously Untreated Patient Study Group. N. Engl J Med 1993; 328: 453-459.

19. Garger S, Severs J, Regan L, Hesslein A, Ignowski J, Wu P.et al. BAY 81-8973, a full-length recombinant factor VIII: manufacturing processes and product characteristics. Haemophilia 2017; 23: e67-e78.

20. Saxena K, Lalezari S, Oldenburg J, Tseneklidou-Stoeter D, Beckmann H, Yoon M et al. Efficacy and safety of BAY 81-8973, a full-length recombinant factor VIII: results from the LEOPOLD I trial. Haemophilia 2016; 22:706-712.

21. Teare J, Sim D, Shah A, Garger S. Increased branching and sialylation of N-linked glycans correlate with an improved pharmacokinetic profile for BAY 81-8973 compared with other full-length rFVIII products. Drug Des Devel Ther. 2019; 13:941-948.

22. Shoah A, Solms A, Garmann D, Katterle Y, Avramova V, Simeonov S, et al. Improved pharmacokinetics with BAY 81-8973 versus antihemophilic factor (recombinant) plasma/albumin-free method: a randomized pharmacokinetic study in patients with severe hemophilia A. ClinPharmacokinet 2017; 56: 1045-1055.

23. Kavakli K, Yang R, Rusen L, Beckmann H, Tseneklidou-Stoeter D, Maas Enriquez M; et al. Prophylaxis vs. on-demand treatment with BAY 81-8973, a full-length plasma protein-free recombinant factor VIII product: results from a randomized trial 
(LEOPOLD II). J ThrombHaemost 2015; 13: 360-9; https://doi.org/10.1111/jth.12828

24. Dargaud Y, Delavenne X, Hart DP, Meunier S, Mismetti P. Individualized PK-based prophylaxis in severe hemophilia. Haemophilia. 2018 Mar;24 Suppl 2:3-17

25. Carcao MD, Iorio A. Individualizing Factor Replacement Therapy in Severe Hemophilia. Semin Thromb Hemost. 2015;41(8):864-71

26. Tagliaferri A, Di Perna C, Santoro C, Schinco P, Santoro R, Rossetti G, et al Cancers in patients with hemophilia: a retrospective study from the Italian Association of Hemophilia Centers. J ThrombHaemost 2012; 10: 90-5.

27. Kamphuisen $\mathrm{P}$, ten Cate $\mathrm{H}$. Cardiovascular risk in patients with hemophilia. Blood. $2014 ; 123: 1297-301$

28. Montalvao SA, Tucunduva AC, SiqueiraLH, Sambo AL, Medina SS, Ozelo MC. et al. Allergic reaction in a cohort of haemophilia $A$ patients using plasma-derived factor VIII (FVIII) concentrate is rare and not necessarily triggered by FVIII. Haemophilia 2015;21(4): e281-5.

29. Lai J, Hough J, Tarrant J, Lillicrap D. Biological considerations of plasma-derived and recombinant factor VIII immunogenicity. Blood. 2017;129(24):3147-3154. 
Table 1: Clinical and HA-related variables of evaluated patients

\begin{tabular}{|c|c|c|c|c|c|c|c|}
\hline Variables & Case 1 & Case 2 & Case 3 & Case 4 & Case 5 & Case 6 & Case 7 \\
\hline Age/sex & $54 / \mathrm{M}$ & $35 / \mathrm{M}$ & $48 / \mathrm{M}$ & $25 / \mathrm{M}$ & $56 / \mathrm{M}$ & $53 / \mathrm{M}$ & $61 / \mathrm{M}$ \\
\hline Weight $(\mathrm{Kg})$ & 102 & 72 & 60 & 62 & 100 & 80 & 61 \\
\hline
\end{tabular}




\begin{tabular}{|c|c|c|c|c|c|c|c|}
\hline $\begin{array}{c}\text { Work and } \\
\text { physical } \\
\text { activity }\end{array}$ & labor worker & employee & labor worker & student & labor worker & Labor worker & \\
\hline $\begin{array}{c}\text { Age } \\
\text { diagnosis (Yr) }\end{array}$ & Infancy & 1 & 2 & 1 & unknown & 27 & 15 \\
\hline HA severity & severe & severe & moderate & severe & mild/moderate & moderate & moderate \\
\hline Target joint & knee, ankle left & knee & $\begin{array}{c}\text { muscular } \\
\text { bleeding inferior } \\
\text { limbs }\end{array}$ & none & none & $\begin{array}{l}\text { ankles, } \\
\text { elbows }\end{array}$ & $\begin{array}{c}\text { knees, ankle } \\
\text { left }\end{array}$ \\
\hline $\begin{array}{c}\text { orthopaedic } \\
\text { evaluation }\end{array}$ & HJHS=25 & $\begin{array}{l}\text { Petterson } \\
13 \mathrm{R}, 10 \mathrm{~L}\end{array}$ & $\mathrm{HJHS}=16$ & HJHS=2 & all negative & HEAD-US & HEAD-US \\
\hline ABR & 3 & 4 & 4 & 1 & 0 & $3-4$ & $2-3$ \\
\hline $\begin{array}{c}\text { Previous HA } \\
\text { treatment }\end{array}$ & $\begin{array}{l}\text { rAHF-PFM } \\
\text { Advate }\end{array}$ & $\begin{array}{c}\text { Pd-FVIII } \\
\text { Haemate-p }\end{array}$ & $\begin{array}{l}\text { rFVIII-FS } \\
\text { Kogenate }\end{array}$ & $\begin{array}{l}\text { rFVIII-FS } \\
\text { Kogenate }\end{array}$ & rFVIII Helixate & $\begin{array}{l}\text { rFVIII-FS } \\
\text { Kogenate }\end{array}$ & $\begin{array}{l}\text { rFVIII-FS } \\
\text { Kogenate }\end{array}$ \\
\hline $\begin{array}{c}\text { Dose } \\
\text { previous } \\
\text { treatment } \\
(\mathrm{Ul} / \mathrm{Kg}) \\
\end{array}$ & 40 & 35 & 50 & 30 & 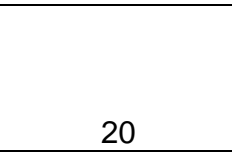 & 30 & 30 \\
\hline $\begin{array}{c}\text { Dose } \\
\text { frequency } \\
\text { (times/week) }\end{array}$ & 3 & eod & twice & 3 & 3 & twice & twice \\
\hline $\begin{array}{l}\text { On demand/ } \\
\text { prophylaxis }\end{array}$ & $\begin{array}{c}\text { on demand } \\
\text { since } 2000, \\
\text { then } \\
\text { prophylaxis }\end{array}$ & on demand & prophylaxis & prophylaxis & prophylaxis & prophylaxis & prophylaxis \\
\hline $\begin{array}{l}\text { Relevant } \\
\text { clinical } \\
\text { history }\end{array}$ & $\begin{array}{l}\text { Related HCV } \\
\text { chronic } \\
\text { hepatitis } \\
\text { treated with } \\
\text { interferon and } \\
\text { ribavirin, } \\
\text { hypertension, } \\
\text { diabetes, } \\
\text { obesity, left } \\
\text { knee } \\
\text { arthorplasty }\end{array}$ & $\begin{array}{c}\text { Severe } \\
\text { allergic } \\
\text { reaction to } \\
\text { pdFVIII, } \\
\text { hypotension }\end{array}$ & $\begin{array}{c}\text { Allergic reaction } \\
\text { to pdFVIII }\end{array}$ & $\begin{array}{l}\text { Recent fall } \\
\text { in FVIII }\end{array}$ & $\begin{array}{l}\text { CVD disease, } \\
\text { PTCA in } \\
\text { treatment with } \\
\text { antiplatelet }+ \\
\text { anticoagulant }\end{array}$ & none & none \\
\hline $\begin{array}{c}\text { Comorbiditie } \\
\text { s }\end{array}$ & $\begin{array}{c}\text { Pancreatic } \\
\text { cancer }\end{array}$ & $\begin{array}{c}\text { HCV related } \\
\text { hepatitis }\end{array}$ & $\begin{array}{c}\text { Hyper- } \\
\text { cholesterolemia }\end{array}$ & none & $\begin{array}{c}\text { Hypertension, } \\
\text { restenosis, } \\
\text { proximal VAT } \\
\text { stenosis, stress } \\
\text { ischemia }\end{array}$ & hypertension & $\begin{array}{c}\mathrm{HCV} \\
\text { negativized in } \\
2014\end{array}$ \\
\hline $\begin{array}{l}\text { Switch date } \\
\text { to Kovaltry }\end{array}$ & Mar 2017 & Apr 2017 & Mar 2017 & Dec 2017 & Sep 2017 & May 2017 & May 2017 \\
\hline $\begin{array}{c}\text { Dose } \\
\text { Kovaltry } \\
(\mathrm{IU} / \mathrm{Kg})\end{array}$ & 45 & 40 & 50 & 30 & 20 & 25 & 30 \\
\hline $\begin{array}{c}\text { Frequency } \\
\text { Kovaltry } \\
\text { (times/week) } \\
\end{array}$ & 2 & $\begin{array}{l}\text { eod; then } \\
\text { twice/week }\end{array}$ & twice & 3 & 3 & twice & twice \\
\hline
\end{tabular}

Legend: HA:Haemophilia A, eod: every other day; HCV: Hepatitis C virus; n.a.: not applicable; PTCA: percutaneous transluminar coro 
